\title{
Lanskap Corak Filsafat Islam
}

\author{
Andi Muhammad Ikbal Salam \\ Institut Agama Islam Negeri (LAIN) Parepare \\ e-mail: muhammad.ikbal1212@gmail.com
}

\begin{abstract}
ABSTRAK. Studi ini menggambarkan sejarah filsafat Islam sebagai salah satu jalan komparasi antara filsafat Barat, sekaligus sebagai jawaban atas polemik sejarah perjalanan ilmu pengetahuan di dunia Islam, di satu sisi ada yang menganggap bahwa ilmu pengetahuan di dunia Islam pernah mengalami kemandegan sebagaimana yang terjadi di Barat, yang lazimnnya disebut sebagai abad pertengahan. Tudingan ini datang baik dari kalangan pemikir Islam sendiri, dan pemikir Barat, di lain sisi ada anggapan bahwa pengetahuan di dunia Islam tidak pernah redup hingga hari ini. Karenanya studi ini dianggap perlu untuk menyodorkan titik terang atas polemik yang terjadi melalui penelusuran sejarah perkembangan filsafat Islam.

ABSTRACT. This study illustrates the history of Islamic philosophy as one of the comparative paths between Western philosophy, as well as the answer to the polemic history of the Historical journey of science in the Islamic world, on the one hand that it considers that science in the Islamic world has experienced the sweetness as it happens in the West, which is Lazimnnya referred to as medieval. The show came both from the Islamic thinkers themselves, and the western thinkers, on the other hand there is the assumption that the knowledge in the Islamic world is never dim to this day. Therefore, this study is deemed necessary to thrusting the bright point of the polemic occurring through the historical search of the development of Islamic philosophy.
\end{abstract}

Kata kunci: Filsafat Islam, Filsafat Barat, Ilmu Pengetahuan.

\section{PENDAHULUAN}

Cicero (106-43 SM), seorang penulis Romawi terkenal pada zamannya dan sebagian karyanya masih dibaca hingga saat ini, mencatat bahwa kata 'filsafat' dipakai Pythagoras sebagai reaksi terhadap kaum cendekiawan pada masanya yang menamakan dirinya 'ahli pengetahuan'. Pythagoras menyatakan bahwa pengetahuan itu begitu luas dan terus berkembang. Tidak ada seorangpun yang mungkin mencapai ujungnya. Jadi, jangan sombong menjuluki diri kita 'ahli' dan 'menguasai' ilmu pengetahuan, apalagi kebijaksanaan. Kata Pythagoras, kita ini lebih cocok dikatakan sebagai pencari dan pencinta pengetahuan dan kebijaksanaan, yakni phylosophia. ${ }^{1}$

Secara terminologi pengertian filsafat menurut para filsuf sangat beragam, Menurut Plato (427-347 SM), filsafat adalah ilmu pengetahuan tentang hakekat. Bagi Aristoteles (384-322 $\mathrm{SM}$ ), filsafat adalah ilmu pengetahuan tentang kebenaran yang meliputi logika, fisika, metafisika dan pengetahuan praktis. Al-Farabi mengartikan filsafat sebagai ilmu tentang alam maujud dan bertujuan menyelidiki hakikat yang sebenarnya. Ibnu Rusyd mengartikan filsafat sebagai ilmu yang perlu dikaji oleh manusia karena dia dikaruniai akal. Immanuel Kant mengartikan filsafat

\footnotetext{
${ }^{1}$ Nur A. Fadhil Lubis, Pengantar Filsafat Umum, (Perdana Publishing, Medan:2015), h. 5
} 
sebagai ilmu yang menjadi pokok pangkal dari segala pengetahuan yang di dalamnya mencakup masalah epistimologi yang menjawab persoalan apa yang dapat kita ketahui. Aristoteles mengartikan filsafat sebagai ilmu yang meliputi kebenaran yang terkandung di dalamnya ilmuilmu metafisika, logika, retorika, etika, ekonomi, politik, dan estetika. Jadi dapat disimpulkan bahwa pengertian filsafat adalah ilmu pengetahuan yang menyelidiki segala sesuatu yang ada secara mendalam dengan mempergunakan akal sampai pada hakikatnya. Filsafat bukannya mempersoalkan gejala-gejala atau fenomena akan tetapi mencari hakikat dari fenomena tersebut.

Lanskap corak filsafat Islam dijabarkan ke dalam corak filsafat peripatetik, filsafat ilmunasi, dan filsafat hikmah al-Muta'aliyat. Epistemologi Barat modern masih memiliki pengaruh besar hampir di seluruh belahan dunia. Sehingga untuk konteks kekinian dibutuhkan epistemologi alternatif yang mampu berdialog secara kreatif dan kritis dengan epistemologi dominan Barat. Karena menurut Mulyadhi prestasi ilmiah yang begitu gemilang dari sains modern semestinya tidak menghalangi untuk melihat sisi-sisi negatifnya, misalnya dalam bentuk implikasi sekulernya terhadap sistem kepercayaan agama Islam². Oleh karena itu, sikap kritis dan waspada harus tetap menyertai sikap apresiatif terhadap sains modern. Namun, Mulyadhi yakin bahwa sikap kritis tersebut tidak akan bisa hadir jika sekiranya hanya menelaah secara sepihak sains modern tanpa perbandingan yang kritis antara epistemologi Barat dengan epistemologi Islam.

\section{METODOLOGI}

Jenis Penelitian ini adalah penelitian kepustakaan. Metode dokumentasi dilakukan untuk memperoleh data-data terkait penelitian. Setelah data diperoleh, teknik analisis data dilakukan menggunakan analisis konten. Kajian mengenai filsafat Islam dan Barat dianalisis hingga menyediakan hasil dan pembahasan.

\section{TEMUAN DAN DISKUSI}

\section{Peripatetik}

Studi ini mengelaborasi analisa Ali Akbar Rasyad, dimana dia melihat perjalanan Rasionalitas Islam telah melewati 5 tahapan.

\section{Periode Pertama}

Negeri Hijaz tidak pernah memiliki latar belakang filosofis, kecuali saat Nabi Ibrahim as, sehingga Hijaz berada dalam kegelapan kebodohan yang membelenggu. Namun, munculnya Islam, cahaya rasionalitas dinyalakan di negeri itu. Ayat-ayat pertama diwahyukan berbicara tentang isu-isu seperti membaca dan menulis, pengetahuan (ilm) dan kebijaksanaan (bikmah), penciptaan, dan antropologi. Dalam suatu cara yang akan mengantarkan manusia untuk berpikir dan meningkatkan kesadarannya. Wahyu-wahyu Islami memandang kebijaksanaan (Hikmah) sebagai pelengkap al-Kitab (al-Quran Suci) dan kitab-kitab suci lainnya. Itulah sebabnya mengapa dalam Islam nalar ('aql) sama berharganya dengan wahyu. Ajaran-ajaran filosofis dan pernyataan-pernyataan rasional membanjiri halaman-halaman seluruh teks Islam.

\footnotetext{
${ }^{2}$ Mulyadhi Kartanegara, 2002. Menembus Batas Waktu "Panorama Filsafat Islam, Cet. I; Bandung: Mizan
} 
Sebagaimana sains-sains Islam lainnya, ajaran-ajaran filosofis Islam tidak tampil dalam kitab lain mana pun selain kitab-kitab suci. Hal tersebut disebabkan karena alasan di antaranya: adalah karena adanya fakta bahwa isu-isu filosofis dan wahyu sangat erat kaitannya sehingga keduanya tidak bisa dipandang sebagai dua isu yang berbeda dalam agama ${ }^{3}$.

\section{Periode kedua}

Matahari hikmah dan pengetahuan mulai memudar pada kegelapan Abad pertengahan di Barat, namun, ia naik di Timur baru (Islam). Dengan kontemplasi dan pemikiran serta perluasan Islam, dengan interpretasi teks-teks dan dogma-dogma keagamaan yang beragam, tak bisa dipungkiri bahwa juga karena kepentingan egois, sehingga melahirkan banyak perselisihan yang beragam dengan fondasi-fondasi proposisi dan ajaran Islam. Implikasinya muncullah mazhab-mazhab filsafat dan teologi Islam yang berbeda. Meskipun demikian, akan tetapi ayat-ayat al-Quran dan hadis-hadis Nabi Saw. yang menyandarkan proposisi-proposisi dan ajaran secara rasional.

\section{Periode ketiga}

Tumbuh kembangnya filsafat dan pengetahuan di dunia Islam. Budaya Islam yang kaya, menarik sains-sains di seluruh dunia. Pencapaian intelektual dari berbagai manusia dan bangsa serta warisan-warisan kebudayaan dari bangsa-bangsa Yunani, Iran, Alexandria (Iskandariyah), Mesir dan India Kuno diterjemahkan secara ekstensif ke dalam bahasa Arab yang merupakan bahasa ilmiah dan bahasa dunia Muslim bahkan sampai sekarang. Gerakan penerjemahan dimulai pada paruh kedua masa Manshur 'Abbasi (136-158/754-775), dan mencapai titik kulminasinya di abad ketiga, dan mulai menyusut pada akhir abad keempat. Sejajar dengan ekspansi yang cepat dari gerakan penerjemahan dan setelah pembangunan bait al-bikmah (graha wicaksana) yang diperintahkan oleh al-Makmun dan dikepalai oleh Yahya bin Masuyah bersama kemunculan para Filosof seperti Abu Yusuf Ya'qub al-Kindi (w. 258-866), yang getol dilakukan adalah penyerapan elemen-elemen hikmah dari peradaban lain ke dalam sistem intelektual Islam dimulai, karenanya, fondasi-fondasi tersebut disiapkan bagi kebangkitan periode keempat rasionalitas Islam ${ }^{4}$. Kemudian disinyalir bahwa filsafat Islam baru menemukan wajahnya yang sistemik dan tertulis sejak al-Kindi yang diberi gelar sebagai filosof Arab pertama. Salah satu sumbangsinya dalam perkembangan filsafat Islam adalah menjembatani pemikiran Islam dengan filsafat Yunani Kuno ${ }^{5}$.

\section{Periode keempat}

Kemudian pada periode keempat ini khususnya pada paruh kedua dikenal karena kehadiran sejumlah filsuf yang diakui dan terkemuka seperti al-Farabi yang dikenal sebagai Abunasir di Barat, dan Ibnu Sina yang dikenal sebagai Avicenna. Dua filsuf ini membawa rasionalisme Islam ke titik tertinggi dalam kekokohan dan kesempurnaanya. Keduanya berhasil menyintesiskan capaian-capain filosofi Yunani-Alexandria dengan ajaran-ajaran keagamaan Islam dan dengan kekuatan pikiran yang genius mereka yang tak tertandingi. Mereka mendirikan dan menyodorkan sistem filsafat yang kokoh selama berabad-abad karya dan

3 Ali Akbar Rasyad, Jurnal Mulla Shadra, (volume II, No. 5. 2012), h. 188

${ }^{4}$ Ali Akbar Rasyad, Jurnal Mulla Shadra, (volume II, No. 5. 2012), h. 188

${ }^{5}$ Muhsin Labib, Pemikiran Filsafat Ayatullah M.T. Mishbah Yazdi (Filsuf Iran Kontemporer) Studi atas Filsafat Pengetahuan, Filsafat wujud dan Filsafat Ketuhanan, (Cet. I; Jakarta: Sadra Press, 2011 ), h. 22 
pemikiran-pemikiran mereka berdua menyuapi Timur Islam dan Barat ${ }^{6}$. Kontribusi al-Farabi terhadap perkembangan filsafat Islam yang dianggap cukup bernilai adalah usaha al-Farabi dalam memberi defenisi dan batasan pada setiap ilmu pengetahuan yang berkembang pada zamannya, dan mengklasifikasi ilmu ke dalam tujuh cabang, yaitu: a. logika, percakapan, matematika, fisika, metafisika, politik, dan ilmu hukum.

Inilah era keemasan filsafat Peripatetik (masya'iyyab) yang cenderung menjadikan mazhab Aristotelian sebagai acuan dibanding platonian. Adapun karakteristik filsafat ini adalah penggunaan argumentasi yang bersifat rasional (Burbani) daripada intuisional (Irfani) atau teologikal (kalami), meskipun demikian, keduanya tetap mempraktikkan hidup zuhud dan tekun dalam beribadah. Sebagaimana yang diketahui Aristoteles bertumpu pada salah satu metode rasionalnya yakni deduksi, maka demikian pula halnya al-Farabi dan Ibn Sina yang bertumpu pada penggunaan deduksi rasional (silogisme), pendasaran pada premis kebenaran primer. Napas filsafat Islam diperpanjang dengan kehadiran dan kontribusi Ibn Rusyd terhadap perkembangan filsafat Islam, apalagi setelah ia melontarkan kritik terhadap al-Gazali melalui karyanya Tahafut al-Tahafut (kerancuan buku tahafut al- Falasifah). Meskipun Ibn Rusyd yang lahir di Cordova, Spanyol ini seorang dokter, namun ia lebih dikenal sebagai seorang filosof. Hani Idris dalam tulisan Muhsin Labib menulis bahwa, Ibn Rusyd memiliki pandangan bahwa filsafat merupakan jalan terbaik untuk mencapai kebenaran sejati dibanding jalan yang dipilih oleh ahli agama, asumsi tersebut membuat kemarahan para ahli agama, sehingga mereka melaporkan pada khalifah tentang gumaman Ibn Rusyd dan meminta agar pemerintah Spanyol mengkafirkan Ibn Rusyd, meskipun perkataan Ibn Rusyd tersebut sebelumnya pernah dilontarkan oleh al-Kindi. Al-kindi mengatakan bahwa kaum fakih tidak dapat menjelaskan kebenaran dengan sempurna karena pengetahuan mereka yang tipis dan kurang bernilai. Pertentangan antara filosof dan kaum ulama berlanjut dan kian memanas setelah al-Gazali menerbitkan karangannya yang berjudul (Tahafut al-Falasifah), kemudian senjata ini pula yang digunakan oleh pihak gereja untuk menghalangi berkembangnya pikiran bebas di Eropa pada zaman Renaissans. Al-Gazali berasumsi bahwa mempelajari filsafat dapat menyebabkan seseorang menjadi atheis, sehingga ia berkesimpulan bahwa hanya ada satu jalan untuk mencapai kebenaran sejati, yakni melalui tasawuf (mistisisme). Namun asumsi al-Gazali tersebut mendapat respon kritis dari Ibn Rusyd dalam karyanya, Tabafut al-Tabafut. ${ }^{7}$ Inilah salah satu perspektif kaitan dengan perjalanan ilmu pengetahuan di dunia Islam, dimana melalui dukungan ulama-ulama klasik terhadap pemerintah kaitannya dengan kampanye anti filsafat yang digencarkan oleh al-Gazali, telah menyebabkan pelarangan pengajaran ilmu filsafat di berbagai perguruan tinggi Islam. Padahal sebagaimana yang terekam dalam sejarah bahwa Ilmu dalam peradaban Islam bermula dengan getolnya beberapa filosof Muslim dalam menerjemahkan literatur-literatur Yunani sehingga pembelajaran filsafat berkembang, akhirnya ilmu dalam peradaban Islam mengalami kemunduran dengan kurangnya perhatian pada filsafat.

\section{Periode kelima}

Setelah perlawanan Ibn Rusyd terhadap gerakan anti filsafat dan logika, maka Barat menganggap telah berakhir masa rasionalisme dalam sejarah Islam. Anggapan ini ternyata

\footnotetext{
${ }^{6}$ Ali Akbar Rasyad, Jurnal Mulla Shadra, op cit, h. 191-192

${ }^{7}$ Muhsin Labib, Pemikiran Filsafat Ayatullah M.T. Mishbah Yazdi (Filsuf Iran Kontemporer) Studi atas Filsafat Pengetahuan, Filsafat wujud dan Filsafat Ketuhanan, h. 23-25
} 
meleset, karena rasionalisme Islam justru semakin bersinar di belahan dunia Islam yang lain. Inilah yang penulis anggap dua perspektif yang berbeda dalam menilai perjalanan sejarah rasionalisme Islam, yakni dalam pandangan sebagain ilmuan muslim dianggap bahwa filsafat mengalami kemunduran, ternyata hasil penelusuran penulis dapat menarik benang merah bahwa dunia Islam tidak pernah mengalami kemunduran atau masa kegelapan ilmu pengetahuan, karena ternyata di dunia Islam yang lain filsafat sedang bangkit dengan kehadiran Hikmah Muta'alliyah yang di cetuskan oleh Mulla Sadra ${ }^{8}$.

\section{Filsafat Iluminasi}

Namun, sebelum Mulla Sadra, lahir sosok Suhrawardi dengan kekhasan konsep iluminasinya, Suhrawdi dilahirkan di Aleppo, Suriah, pada 1154 dan ia dihukum mati oleh Shaladin pada 1191 karena Suhrawardi dituduh kafir dan demi menjawab para tuntutan kaum teolog maupun fuqaha. Bagi Suhrawardi upaya yang ia lakukan adalah untuk menjelaskan pendapatpendapatnya selaras dengan metode Peripatetik konvensional. Peripatetik konvensional olehnya disebut sebagai metode diskursif yang baik, hanya saja tidak memadai dalam mencapai tujuan pencari Tuhan yang ingin sampai pada tingkat pengalaman kebijaksaan ataupun hikmah, atau yang ingin mengintegralkan metode diskursif dan pengalaman batin. Hikmah yang didasarkan pada dualisme cahaya dan kegelapan, menurut Suhrawardi adalah merupakan warisan para guru mistis Persia, seperti Jamasp, Frashaustra, Bizrgimher, dan para pendahulunya. Dimana hikmah ini juga terwakili di Barat, di antaranya adalah Plato, Agathadaimon, dan Ascelepius. Al-Bisthami dan al-Hallaj kemudian melanjutkan tradisi ini. Hingga puncaknya ada pada diri Suhrawardi. Adapun inti dari hikmah iluminasi bagi Suhrawardi adalah "ilmu cahaya" yang membahas sifat dan cara pembiasan cahaya. cahaya tersebut menurutnya, tidak bisa didefenisikan karena cahaya merupakan realitas yang paling nyata. Disamping cahaya juga merupakan realitas yang menerangi segala sesuatu. Cahaya ini pun merupakan substansi yang masuk ke dalam komposisi semua substansi yang lain fisika ataupun metafisika. Segala sesuatu selain "Cahaya Murni," terdiri atas wujud yang membutuhkan penyangga, yang disebutnya sebagai substansi gelap atau bentuk (form) substansi yang merupakan kegelapan itu sendiri. Objek-objek yang menerima cahaya sekaligus kegelapan olehnya disebut barzakh. Ia merupakan kegelapan murni dimana semua cahanya berasal dari sumber luar.

Cahaya ketika dihubungkan dengan objek-objek yang ada di bawahnya ia memiliki dua bentuk, yaitu cahaya terang pada dirinya sendiri dan cahaya yang terang dan menerangi selain dirinya. Cahaya yang terakhir menerangi segala sesuatu. Karena bagaimanapun statusnya cahaya tetaplah sesuatu yang terang, dan ia merupakan sebab tampaknya segala sesuatu yang pasti beremanasi darinya. Karenanya ia memiliki sifat hidup sebab kehidupan tidak lain dari penampakan diri yang esensial pada segala sesuatu selainnya. Namun, dari semua manifestasi wujud terdapat cahaya-cahaya murni, yang membentuk jalur menaik, bagian tertingginya adalah Cahaya di atas cahaya yang menjadi sumber eksistensi semua cahaya yang berada di bawahnya. Cahaya di atas cahaya ini juga bersifat mandiri, tunggal. Karena jika diasumsikan dua cahaya primer maka kita akan terjebak ke dalam kontradiksi bahwa keduanya harus berasal dari cahaya ketiga yang mesti bersifat tunggal'.

\footnotetext{
${ }^{8}$ Muhsin Labib, Pemikiran Filsafat Ayatullah M.T. Mishbah Yazdi (Filsuf Iran Kontemporer) Studi atas Filsafat Pengetahuan, Filsafat wujud dan Filsafat Ketubanan, h. 27

9 Majid Fakhry, Sejarah Filsafat Islam”'Sebuah Peta Kronologis", (Cet. I; Bandung, Mizan, 1997), h. 130-131
} 


\section{Hikmah al-Muta'aliyat}

Kemudian periode kelima, inilah periode dimana perjalanan rasionalitas Islam atas filsafat di warnai oleh filosof terkemuka yakni Mulla Sadra, dan dalam periode inilah Mulla Sadra memberikan pengaruh besar dalam perjalanan perkembangan filsafat Islam. Secara keliru sebagian orang mempercayai bahwa karya Mulla Sadra merupakan suatu adaptasi yang cerdas namun tidak inovatif, dari pemikiran peripatetik dan secara khusus dari mazhab Ibnu Sina, demikian pula yang lainnya menganggap mazhab Mulla Sadra sebagai perluasan dari mazhab iluminasionis, secara khusus filsafat Suhrawardi. Bangunan filsafat Mulla Shadra hanya dianggap sebagai usaha integrasi tidak konsisten atas tiga ranah epistemologis dari peripatetik, iluminasionis, teologi, dan mistisisme, atau bahkan dari empat mazhab (peripatetik, iluminasionis, teologi dan mistisisme). Namun, apa yang ada dibalik tiga sudut pandang ini adalah merupakan pandangan yang keliru, hal tersebut merupakan kesalahpahaman terhadap ciri-ciri dan sifat dari filsafat Mulla Sadra.

Anggapan tersebut bisa ditepis dengan salah satunya meminjam pengakuan Alparslan Acikgence sebagaimana yang dikutip oleh Muhsin Labib, bahwa al-Hikmah Muta'aliyyah sebagai aliran baru yang dirumuskan oleh Mulla Sadra melahirkan dimensi intelektual baru yang bukan hanya sekedar ensiklopedia sdialektis (menghimpun secara dialogis dan kritis berbagai teori dan pandangan) melainkan juga penafsiran segar dari berbagai khasanah tradisional. Sintesis yang di lakukan oleh Mulla Sadra bukan sekedar kompromi dangkal, akan tetapi melalui suatu prinsip filosofis ${ }^{10}$.

Lewat pengantarnya atas Asfar, karya terbesar Mulla Sadra dan ensiklopedi Muslim paling komprehensif, setelah membicarakan kehidupan ilmiah dan spiritualnya sendiri, dan secara eksplisit mengeluhkan ketidakadilan dunia terhadap hikmah dan kekerasan dari para sejawatnya sendiri, melalui retorika dan gaya spiritualnya seolah mengingatkan kita pada perkataan Ali bin Abi Thalib, dia menunjuk periode-periode praktis asketiknya yang panjang dan bagaimana kebenaran-kebenaran disingkapkan kepadanya. Mulla Sadra melihat perubahan ini sebagai karunia Ilahi dan mengurai sifat dan spesifikasi mazhabnya sendiri dalam suatu jalan mistis. Mengenai sumber dan sifat mazhabnya, Shadra mengatakan:

"Maka ketika aku secara tulus berpaling kepada Allab pembuat sebab, dan melalui watak primordialku (fitrah), aku bermohon kepada hadirat-Nya, yang membuat selurub kesulitan menjadi mudah. Untuk waktu yang lama, aku berkhalwat; kemudian, berkat periode praktis askestisku yang lama, batiku dibakar dan diterangi dengan cabaya dunia spiritual (al-malukut) dan bayangan dunia imajinal (al-jabarut) dilemparkan atasnya. Kemudian aku menyadari rahasia-rabasia yang sebelumnya tidak aku sadari; rahasia-rahasia disingkapkan untukku yang sebelumnya belum disingkapkan sedemikian demonstratif. Melalui intuisi, aku melihat dan menemukan rahasiarahasia keTubanan realitas rububiyahyang kekal terselubung dan wali-wali Tuban yang sebelumnya telah aku pelajari”.

Begitu besar pengaruh Mulla Shadra terhadap pemikiran Islam sehingga apa yang disumbangkan ke dalam konteks pengetahuan dan hikmah Islam tidak dapat disejajarkan dalam sejarah Islam, sekalipun kelebihan yang diutamakan dalam periode ini milik al-Kindi, alFarabi, Ibn Sina dan Suhrawardi, apa yang mereka kontribusiskan tidak pernah dapat dibandingkan dengan perubahan dan perkembangan yang Mulla Sadra munculkan di medan pemikran Islam. Dalam metodologi, struktur dan konten, dia melakukan perubahan yang tidak biasa.

${ }^{10}$ Muhsin Labib, Filosof Sebelum dan Sesudah Mulla Shadra, op cit, h. 34 
Perubahan yang dilakukan Mulla Sadra yang bersifat kontekstual dan kualitatif adalah lebih baik ketimbang seluruh inovasi yang dibuat dalam sepanjang tujuh abad dari periode ketiga dan keempat dari filsafat dan rasionalitas Islam. Munculnya Mulla Sadra menampik klaim dari para orientalis yang mengira bahwa filsafat Islam, setelah memperoleh serangan sengit dari al-Gazali, sehingga tidak pernah lagi muncul, dan bahkan usaha dari Ibn Rusyd merupakan usaha-usaha terakhir dan tidak berhasil dari apa yang dilakukan oleh para filsuf Muslim untuk membela filsafat, dan bahwa setelahnya, filsafat Islam tetap mengalami stagnasi/kemandulan. Kehadiran filsafat Sadrian sudah barang tentu berbarengan dengan renaissans dan kemunculan filsafat modern di Barat di satu sisi dan mundurnya status ilmiah ummat Muslim di sisi lain. Karena perbuatan buruk yang memang disengaja dari Barat sehingga filsuf terkemuka ini tetap dalam ketidakjelasan di Barat. Sebagaimana yang dikutip oleh Muhsin Labib, Jalal al-Din Asytiani menjelaskan bahwa Barat mempunyai tendensi di balik anggapannya tersebut. Barat mengagungkan Ibn Sina dan Suhrawardi karena keduanya dianggap pewaris filsafat Barat Kuno (Yunani Kuno), sedangkan Mulla Sadra tidak mendapat perlakuan setimpal di Barat karena menggagas filsafat yang orisinal dan berbasis pada kesyi'ahannya.

Kemudian ketika dirunut ke belakang, pemikiran Islam kritis apabila ditentukan suatu rekonstruksi suatu mazhab filsafat dan intelektual sepanjang garis pengetahuan dan tantangan dari zamannya sebagai usaha memformulasi dan menyunting ulang mazhab itu sembari memelihara prinsip-prinsip pokok dan elemen-elemen fundamentalnya, maka secara tepat dapat dikatan bahwa gerakan filsafat baru di Iran sebagai "mazhab Neo Shadrian.

\section{PENUTUP}

Melalui konstruksi gagasan yang berdasar pada bangunan filsafat Islam, status ontologis tidak hanya terbatas pada obyek-obyek empirikal sebagaimana apa yang telah disimpulkan oleh positivisme bahwa realitas yang ada hanyalah sejauh apa dapat dijangkau oleh panca indra melalui observasi dan verifikasi empirikal, namun juga pada obyek-obyek metaempirik, dan obyek-obyek ilmu juga berpadanan dengan hierarki wujud. Semakin tinggi posisi wujud dalam hierarki wujud, maka semaikin nyata dan fundamental status ontologisnya. Karena obyekobyek metaempirik menduduki posisi yang lebih tinggi

\section{REFERENSI}

Fakhry, Majid Fakhry. (1997). Sejarah Filsafat Islam”Sebuah Peta Kronologis", Cet. I; Bandung, Mizan

Kartanegara, Mulyadhi. 2002. Menembus Batas Waktu "Panorama Filsafat Islam, Cet. I; Bandung: Mizan

Labib, Muhsin, Filosof Sebelum dan Sesudah Mulla Shadra, Cet. I; Jakarta: al-Huda, 2005

Labib, Muhsin, 2011. Pemikiran Filsafat Ayatullah M.T. Mishbah Yazdi (Filsuf Iran Kontemporer) Studi atas Filsafat Pengetabuan, Filsafat wujud dan Filsafat Ketubanan, Cet. I; Jakarta: Sadra Press

Lubis, Nur A. Fadhil. 2015. Pengantar Filsafat Umum, Medan: Perdana Publishing

Rasyad, Ali Akbar. 2012. Jurnal Mulla Shadra, volume II, No. 5. 